\title{
Infiltration liquid crystal in microstructured polymer optical fibers
}

\author{
Yuan, Scott Wu; Wei, Lei; Bang, Ole
}

Published in:

Conference proceedings, CLEO/Europe - EQEC

Link to article, DOI:

10.1109/CLEOE-EQEC.2009.5192749

Publication date:

2009

Document Version

Publisher's PDF, also known as Version of record

Link back to DTU Orbit

Citation (APA):

Yuan, S. W., Wei, L., \& Bang, O. (2009). Infiltration liquid crystal in microstructured polymer optical fibers. In Conference proceedings, CLEO/Europe - EQEC IEEE. https://doi.org/10.1109/CLEOE-EQEC.2009.5192749

\section{General rights}

Copyright and moral rights for the publications made accessible in the public portal are retained by the authors and/or other copyright owners and it is a condition of accessing publications that users recognise and abide by the legal requirements associated with these rights.

- Users may download and print one copy of any publication from the public portal for the purpose of private study or research.

- You may not further distribute the material or use it for any profit-making activity or commercial gain

- You may freely distribute the URL identifying the publication in the public portal 


\title{
Infiltration Liquid Crystal in Microstructured Polymer Optical Fibers
}

\author{
W. Yuan ${ }^{1}$, L. Wei ${ }^{1}$, O. Bang ${ }^{1}$ \\ 1. DTU Fotonik, Dept. of Photonics Engineering, Technical University of Denmark, DK-2800 Kgs. Lyngby, Denmark
}

Microstructured polymer optical fibres (mPOFs) have attracted significant interests, mainly because fabrication techniques have allowed novel structures to be made at low temperature with polymers, especially PMMA (refractive index 1.49) [1]. Recently, thermal and electrical tunabilities of liquid crystals infiltrated silica photonic bandgap fibres have been demonstrated, and various devices have also been developed [2,3].

Here, to our knowledge, we firstly demonstrate the photonic bandgap effect with PMMA mPOF by filling the air holes with liquid crystal, and subsequently change the light guidance mechanism from index guiding to bandgap guiding. The triangular structure PMMA mPOF used in the experiment is fabricated by our group with diameter $130 \mu \mathrm{m}$ and a solid core surrounded by 3 rings of air holes, as shown in Fig. 1(a) the air hole diameter and hole to hole pitch are $4.5 \mu \mathrm{m}$ and $10 \mu \mathrm{m}$, respectively. A $60 \mathrm{~cm}$ length $\mathrm{mPOF}$ is butt-coupled to a conventional single mode fiber (SMF) with the broadband light from a supercontinuum source (SuperK, Koheras A/S). The guided modes image under 50X microscope is shown in Fig. 1(b). It is clear to see the colour of the guided modes is red, since some wavelengths are attenuated by the material loss of PMMA in visible region. A positive dielectric anisotropy liquid crystal E7 (Merck, Germany, $\mathrm{n}_{\mathrm{o}}=1.52, \mathrm{n}_{\mathrm{e}}=1.74$ ) is then infiltrated into about $6 \mathrm{~cm}$ of the length of mPOF by using capillary forces with the duration of 45 minutes. The end of mPOF where liquid crystal is filled is then butt-coupled again with SMF. After liquid crystal infiltration, the guided modes image is shown in Fig. 1(c), and it is found the colour of the guided modes is changed from red to green, which means some wavelengths in red region have been filtered out due to the bandgap effect induced by liquid crystal. The transmission spectrum is measured by an optical spectrum analyzer with $1 \mathrm{~nm}$ resolution, and normalized to that of the unfilled fiber as shown by the solid line in Fig. 1(d). The difference of spectra of Fig. 1(d) clearly reveals that, by filling the liquid crystal, some new bandgaps are formed in the wavelength range of $730 \mathrm{~nm}-780 \mathrm{~nm}$, which is quite different with the material loss spectrum shown as the black dash line.

The possibility of applying mPOF to fabricate turnable fiber devices will make mPOF as an ideal substitution of the expensive silica photonic crystal fibers in practical applications. More investigations will be done in near future, e.g. thermal and electrical tunabilities.

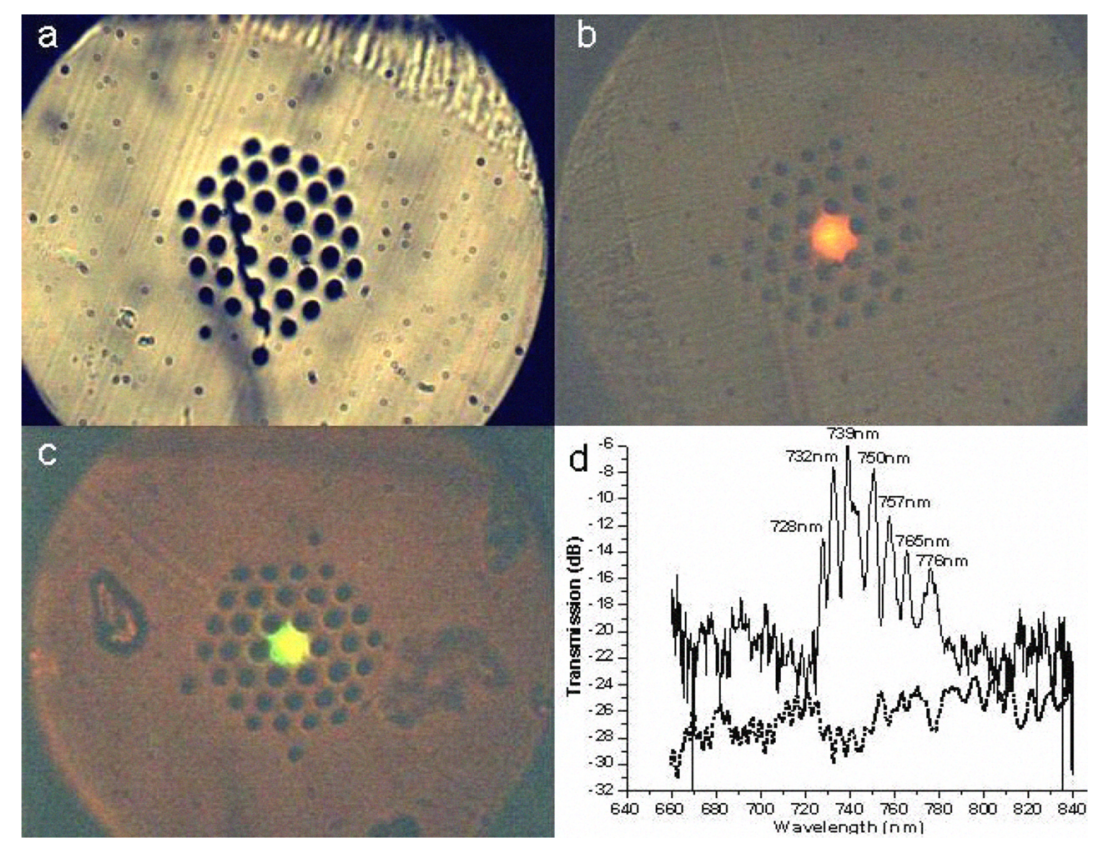

Fig. 1 (a). The cross section of the mPOF used in this experiment. (b) The guided modes image of unfilled mPOF with the broadband light from a supercontinuum source. (c) The guided modes image of E7 filled mPOF. (d) Transmission spectrum of liquid crystal filled mPOF (the solid line) and material loss spectrum of mPOF (the dash line).

\section{References}

[1] M. Large, L. Poladian, G. Barton, M. Eijkelenborg, "Microstructured polymer optical fibres," Springer, (2008).

[2] T. T. Alkeskjold, L. Scolari, D. Noordegraaf, J. Laegsgaard, J. Weirich, L. Wei, G. Tartarini, P. Bassi, S.Gauza, S. Wu, A. Bjarklev, "Integrating liquid crystal based optical devices in photonic cystal fibers," Opt. Quant. Electron. 39, 1009 (2007).

[3] L. Wei, L. Eskildsen, J. Weirich, L. Scolari, T. T. Alkeskjold, and A. Bjarklev, "Continuously tunable all-in-fiber devices based on thermal and electrical control of negative dielectric anisotropy liquid crystal photonic bandgap fibers," Appl. Opt. 48, 497-503 (2009). 